\title{
Characteristics Research of Fuyu-Yangdachengzi Oil Layer Fault System of Northern Xingshugang
}

\author{
Ping $L i^{1, a}$ \\ ${ }^{1}$ Daqing Oil Field Co., Ltd. Fourth Oil Production Plant Geological Brigade, 163511 \\ ${ }^{a}$ email
}

Keywords: Fuyu-Yangdachengzi Oil Layer, Fault System

\begin{abstract}
By studying the northern Xingshugang Fuyu-Yangdachengzi Oil Layer faults basic elements, determine fault combination mode; through the study of fault growth index, determine fault activity period; Combined with the fault formation and evolution history, northern XingshugangFault System is divided into six types and object layer Fuyu oil major fault system consists of four sets of components.
\end{abstract}

\section{Introduction}

Northern Xingshugang Fuyu-Yangdachengzi Oil Layer structure is located in the northern part of the Central Depression of Songliao Basin, northern Daqing Changyuan Xingshugang anticline, west Qijia - Gulong sag, east Sanzhao depression. Now widely recognized Northern Xingshugang anticline structure steeper West Wing, East Wing constructed more moderate and relatively flat anticlinal axis, according to this feature can be divided into the western slope belt, eastern and central anticline belt with a gentle slope.

\section{Fault Geometry Features}

Songliao Basin from the Cretaceous to Neogene unconformity development 8, but have a major impact on the sedimentary and tectonic evolution of mainly two, namely T4 and T03, based on typical unconformity surface level reflected on the vertical northern Xingshugang can be divided into three structural layer, bottom layer is constructed are trapped off Huoshiling Yingcheng constituted tectonic depression Denglouku Nenjiang constituted Sifangtai $\sim$ Neogene constituted inversion layer structure.

Strike of the fault and the fault density. Characteristics to determine fault orientation of the stress field can indirectly reflect regional stress field direction, particularly freshmen orientation towards secondary faults more intuitive. Fault density reflect the size of the size of the fault deformation strength, especially in the rift basin evolution stage, breaking the scale and development of depression is relatively small compared to the fault, often through statistical fault density can indirectly reflect the size of the fault deformation strength . Depression of fault density, followed by reverse phase faulted minimum of fault density, fault density depression of bottom-up which is gradually reduced, indicating that more of the characteristics of fault activity.

Scale faults and fault mode combination. A size fault can be released by breaking away from the vertical and extending the length of the two parameters to reflect together. Overall, northern Xingshugang fault size mix, throw different sizes, extending from the varying lengths, showing more of the nature of faulting.

Fault mode is a combination of the nature of the basin, the stress field characteristics and comprehensive reflection of rock capable of analyzing a combination of fault mode helps study the formation and evolution of the basin fault. northern Xingshugang peace sectional surface fault presents a specific combination mode. Rift multi-layer type main causes of stretch, combined to form a cross-sectional tomographic fault terrace or half-grabens formed by the combination of the reverse secondary regulator faults, parallel or duplicative side column combinations on a flat surface reflects the extensional deformation characteristics. 
With dense fault. According to the study area $16 \times 16$ seismic interpretation results, fault density with detailed tracking contrast, the final determination of the study area Fuyu-Yangdachengzi Oil Layer dense with a total of 18 development, which mainly north west, near EW 3 , NE 1. With dense distribution of fault in the East Dorsey few features in the development of the northwest slope only two dense band, it was NW direction, and are extending into the southwestern tip of the central anticline belt; central anticline belt development 5 , to the NW or NNW; eastern gentle slope with 10 development towards multi-directional, mainly NW direction. Fault usually dense with internal graben, and dense as the corresponding band between Horst, a large area with intensive development of fault makes northern Xingshugang Fuyu-Yangdachengzi Oil Layer formed graben - horst structure.

\section{Faulting Period and the Formation and Evolution of History}

Faulting Period. Progressive deformation is not static, different deposition phase fault strength of its activities is different. Due to structural deformation it determines the formation fault development, thereby forming period corresponding to fault; use of fault deformation and fault growth index is determined faulting period.

When the fault growth index is greater than 1, the fault activity during this period, and the greater the growth index, the more intense fault activity. Select 4 north to south survey lines sectional growth index compiled from the same raw statistical regularity faults see:. A faulted group of Stone Mountain Yingcheng fault formation and ongoing activities, associated portion of the secondary fault formation; b Depression fault mainly in Qingshankou Yaojia period and strong activity, part of the rift fault resurrection, Sec Nenjiang a period of relatively weak activity;. c of the inversion, seismic data can not be due to restrictions by the growth exponential profile reflect. Integrated cross-section shows that the growth index for Yingcheng Huoshiling during the deposition, the deposition Qingshankou period Yaojia and Nenjiang first two stages and three, respectively, during the deposition of the sedimentary period of Nenjiang strong activity before fault northern Xingshugang .

Fault extensional deformation process, in addition to vertical displacement occurs, the horizontal direction is also accompanied by dislocation arising from stretch displacement amount. Extending horizontally volume statistics in the study area four typical cross-section, and calculate the rate of stretching and stretching speed parameter, shows four peaks characteristic: that Huoshiling Yingcheng, Qingshankou, Yaojia, a tender, two segment. The first period corresponds to a rift basin evolution stage, Qingshankou, Yaojia tender and the first two stages during the deposition of the corresponding depression stages of evolution.

By the reflection of the failure strain of times, the three sedimentary Nenjiang strong activity during the previous northern Xingshugang fault were Yingcheng Huoshiling during the deposition, the deposition Qingshankou period, and during the deposition of Nenjiang Yaojia a group, during the deposition of Sec.

\section{The Formation of Fault and Its Evolution History}

Formation and evolution process and features of the stratigraphic sequence analysis, combined with structural geometry balanced section obtained can clear break - through the study area structure. Studies suggest that fault the formation and evolution of the study area has experienced Huoshiling $\sim$ camp city group extended period of deformation, Denglouku $\sim$ Nenjiang period transtension deformation, deformation tender forty-five reversed during the deposition of the three big stage fault deformation characteristics of different stages of the evolution of different, reflecting differences in regional stress field fault the formation and evolution.

Early Cretaceous, the central basin Mo beans abnormal mantle surface arched so obvious, resulting in continued tension. In the main stretch of Shahezi form a new rift, mainly north-east, north-northeast trending. Fault occurs mainly extensional deformation in NNW-NEE tensile stress field, the main fault was nearly north-south trending. Huoshiling - Yingcheng sedimentary basin 
evolution during strong rifting phase, the larger the intensity of fault activity and its late depression, reversal of part of the ongoing activity occurs superimposed deformation controlled the structural evolution of the northern Xingshugang.

Denglouku sedimentary basin during the evolution into the depression stage, filling the region stable distribution strata, faulting weak strata cover large areas on the Basin and Range advance into depression tectonic evolution stage; Qingshankou and Yaojia deposition Depression during basin evolution continues, filling stratigraphic distribution of the region's stability, faulting representing Denglouku spring and during the deposition of the first group to strengthen this stage secondary faults, showed another strong sustained transtension activities in the past under the EW extensional stress field, T2 with dense fault - "like a flower" structure were formed during this period, breaking a nearly north-south direction; when a two-stage deposition of Nenjiang fault basic activities are continuing, but the intensity of the activity significantly weakened.

Basement fault active again, Nenjiang stage structure had started to return, occurred late Mingshui strongly deformed sedimentary Daqing Changyuan formed anticline, Ming deformed shape denuded inversion structure, the late Paleogene inversion weakened, eventually forming today construction.

\section{Fault System Division}

For faults zone, especially in the case of extremely complex fault, in a certain area, the activities of different periods and different fault deformation properties on behalf of its specific genetic mechanism. When analyzing the impact fault of hydrocarbon accumulation and aggregation of the same causes rupture often have the same control Tibetan characteristics, therefore, the research division of Fault System fault control many Tibetan characteristics can greatly reduce the workload of each study are broken and for controlling characteristics of Tibetan complex fault can also clearly be in control.

Fault System Type. According to fault formation during the deformation characteristics (stretching, twisting and Zhang reverse) and the formation and evolution mechanism, northern XingshugangFault System can be divided into six types, namely early extensional fault ( I type), medium-term Zhang twist fault (II type), late reverse faults (iii type), extended early - mid Zhang twist fault ( $\mathrm{i}$ - ii type), Zhang twist mid - late reverse fault (ii -iii type), extended early - mid transtension - advanced reverse fault ( $\mathrm{i}$ - ii - iii type).

I type Fault System fault - mainly in the activities of fault in Huoshiling Yingcheng development during the deposition of fault; type II Fault System fault mainly depression of activity, a single off the tender underside of three sections, Sec tender a bottom surface, a bottom surface and Yaojia Qingshankou bottom or off the three break through boundaries and less these faults in a two-stage during the event Nenjiang formation is the main type of fault System; iii type fault system mainly reversal of fault activity, a single off the end of Paleogene boundary, break out the bottom boundary of the water group, or the end of Nenjiang said three reflective layers, these faults are formed in the main event since reverse Nenjiang deposition, this type of fault in the whole area is less developed.

In the six sets of Fault System, the composition of Fuyu-Yangdachengzi Oil Layer mid sheets were twisted fault ( II type), extended early - mid Zhang twist fault ( I - II type), Zhang twist mid - late reverse fault ( II -III type) and stretching the early - mid transtension - advanced reverse fault ( i - ii -iii type) 4 sets of fault System. Accordingly, the study area Fuyu-Yangdachengzi Oil Layer fault in plane divided into four types, each share in different proportions fault sets, mid Zhang twist fault (II type) for the faults in the area the most important part, 81.9\% transtension mid - late reverse fault (ii - iii type) and stretching the early - mid Zhang twist fault ( i - ii type) less, accounting for $14.39 \%$ and $2.68 \%$, respectively, extending long-term activities of the early mid-term Zhang twist - advanced reverse fault ( i - ii - iii type) least developed, accounting for only $0.98 \%$, indicating fault - and not through the depression of the vertical fault. 


\section{Conclusion}

The study area of fault is mostly straight normal fault, north to the west, a small amount of NWW. Smaller faults, throw generally less than $100 \mathrm{~m}$, extending the length of less than 6km. Fault density, reached 0.13 / km2;

Subject to the impact of structural inversion, the central anticline belt fault was dense with the overall back-shaped feature. A total rupture with intensive stretching and twisting Causes Causes two genetic mechanisms, the study area Parallel intensive graben extending the main causes, a small part of the formula for the parallel graben and twisting causes mixed dense band;

Northern Xingshugang fault formation and evolution of the main periods: the faulted phase (Early Cretaceous), depression period (Qingshankou deposition early Yaojia tender and the first two stages during the deposition), inversion of configuration (Nenjiang sedimentary late, and Mingshui late Paleogene sedimentary late). Intense faulting during the early Early Cretaceous sedimentary Qingshankou early and late Mingshui deposition;

Northern XingshugangFault System is divided into six types, object Fuyu oil layer is mainly composed of type II, I - II type, II -III and type, I - II -III type consisting of four sets of Fault System;

\section{References}

[1] Wang Xue. Basin Qijia sag and Daqing Changyuan Fuyu-Yangdachengzi Oil Layer oil source [J]. Petroleum Exploration and Development, 2006,33 (3): 294-298.

[2] Huang Chunyi. Northern Xingshugang Fuyu-Yangdachengzi Oil Layer sedimentary facies and its Forecast [J]. Oil and Gas Technology, 2011, 33 (5): 161-164. 